\title{
Ionic liquid for high temperature headspace liquid-phase microextraction of chlorinated anilines in environmental water samples
}

\author{
Jin-feng Peng, Jing-fu Liu, Gui-bin Jiang*, Chao Tai, Min-jia Huang \\ Key Laboratory of Environmental Chemistry and Ecotoxicology, Research Center for Eco-Environmental Sciences, \\ Chinese Academy of Sciences, P.O. Box 2871, Beijing 100085, China
}

Available online 8 December 2004

\begin{abstract}
Based on the non-volatility of room temperature ionic liquids (IL), 1-butyl-3-methylimidazolium hexafluorophosphate ([C $\left.{ }_{4} \mathrm{MIM}\left[\mathrm{PF}_{6}\right]\right) \mathrm{IL}$ was employed as an advantageous extraction solvent for high temperature headspace liquid-phase microextraction (LPME) of chloroanilines in environmental water samples. At high temperature of $90^{\circ} \mathrm{C}$, 4-chloroaniline, 2-chloroaniline, 3,4-dichloroaniline, and 2,4-dichloroaniline were extracted into a $10 \mu \mathrm{l}$ drop of $\left[\mathrm{C}_{4} \mathrm{MIM}\right]\left[\mathrm{PF}_{6}\right]$ suspended on the needle of a high-performance liquid chromatography (HPLC) microsyringe held at the headspace of the samples. Then, the IL was injected directly into the HPLC system for determination. Parameters related to LPME were optimized, and high selectivity and low detection limits of the four chlorinated anilines were obtained because the extraction was performed at high temperature in headspace mode and the very high affinity between IL and chlorinated anilines. The proposed procedure was applied for the analysis of the real samples including tap water, river water and wastewater samples from a petrochemical plant and a printworks, and only 3,4-dichloroaniline was detected in the printworks wastewater at $88.2 \mu \mathrm{g} \mathrm{l}{ }^{-1}$ level. The recoveries for the four chlorinated anilines in the four samples were all in the range of $81.9-99.6 \%$ at $25 \mu \mathrm{g}^{-1}$ spiked level.
\end{abstract}

(C) 2004 Elsevier B.V. All rights reserved.

Keywords: Headspace liquid-phase microextraction; High temperature; Ionic liquid; Chlorinated anilines; Wastewater

\section{Introduction}

Chlorinated anilines were widely used in a variety of industries [1-3] and are often found in wastewater discharged from these plants. As these substances are suspected cancerogenous and highly toxic to aquatic organisms or human beings [4-5], most of them have been included in list of priority pollutants by the US Environmental Protection Agency (EPA).

High-performance liquid chromatography (HPLC) is most frequently used for the determination of chlorinated anilines [6-8], and sample pretreatment is usually required. Current sample pretreatment methods for wastewater samples involve solid-phase extraction (SPE) [9], solid-phase microextraction (SPME) [10], liquid-liquid extraction (LLE) [11], and supported liquid membrane extraction (SLM) [12]. A derivatization step, however, was usually required in SPE

\footnotetext{
* Corresponding author.

E-mail address: gbjiang @ mail.rcees.ac.cn (G.-b. Jiang).
}

and SPME because of the strong polarity and high solubility of the analytes.

In our previous study [13-14], ionic liquids (IL) were used for liquid-phase microextraction (LPME) of some organic pollutants. The main advantages of IL for LPME were the applicability of long-term headspace extraction due to the non-volatility of IL, and the compatibility with HPLC due to the non-harmfulness of IL to HPLC column. In this present study, 1-butyl-3-methylimidazolium hexafluorophosphate $\left(\left[\mathrm{C}_{4} \mathrm{MIM}\right]\left[\mathrm{PF}_{6}\right]\right)$ IL was demonstrated to be a suitable extraction solvent for high temperature headspace LPME of chlorinated anilines in environmental water samples.

\section{Experimental}

\subsection{Reagents and chemicals}

HPLC-grade acetonitrile was purchased from Dikma (Dikma, China). Standard stock solutions $\left(1000 \mathrm{mg} \mathrm{l}^{-1}\right)$ of 
4-chloroaniline (4-CA), 3,4-dichloroaniline (3,4-DCA), and 2,4-dichloroaniline (2,4-DCA) (Acros Organics, Belgium), as well as 2-chloroaniline (2-CA) (Tokyo kasei Kogyo, Japan) were prepared by dissolving $0.025 \mathrm{~g}$ of the compounds in $25 \mathrm{ml}$ acetonitrile. The solutions were stored in brown glass bottles and kept at $4{ }^{\circ} \mathrm{C}$. Fresh working solutions $\left(10 \mathrm{mg} \mathrm{l}^{-1}\right)$ were prepared daily by appropriate dilution of the stock solutions. Reagents for synthesis of $\left[\mathrm{C}_{4} \mathrm{MIM}\right]\left[\mathrm{PF}_{6}\right]$ including 1methylimidazole (99\%), 1-chlorobutane (99\%) and hexafluorophosphoric acid $(60 \mathrm{~m} \%$ solution in water) were obtained from Acros Organics. The synthesis and physicochemical properties of $\left[\mathrm{C}_{4} \mathrm{MIM}\right]\left[\mathrm{PF}_{6}\right]$ IL were described in our previous study [13]. All of the other chemicals and solvents were of analytical reagent grade and ultrapure water (EASY-pure LF) was used throughout.

\subsection{Extraction procedure}

The extraction procedure is the same as that described in our previous study [13], except that a $10 \mu \mathrm{lL}$ drop was used as extractant and $50 \mathrm{ml}$ flask was adopted for holding $20 \mathrm{ml}$ of sample solution, and the flask with sample solution was placed in recycling hot water to control the extraction temperature. The hot water was provided by a thermo bath system (TB-85 Thermo Bath, Shimadzu, Japan) setting at expected temperature.

\subsection{HPLC determination}

The LC-VP liquid chromatographic instrument (Shimadzu, Japan) consists of an SCL-10Avp system controller, two LC-10ATvp pumps, and an SPD-M10Avp detector setting at $240 \mathrm{~nm}$. Samples were injected with a $7725 \mathrm{i}$ manual injection valve with a $20 \mu l$ loop (Rheodyne, USA). Detection was achieved by the technique of photodiode array detection. Data acquisition and process were accomplished with a Class-VP Workstation (Shimadzu, Japan). The analytical column was a $250 \mathrm{~mm} \times 4.6 \mathrm{~mm}$ i.d. $\mathrm{C}_{18}$ column (Inertsil ODS-P, GL Sciences Inc., Japan, $5 \mu \mathrm{m}$ particles). The mobile phase was a mixture of acetonitrile-water $(50: 50, \mathrm{v} / \mathrm{v})$ delivered at a flow rate of $1.0 \mathrm{ml} \mathrm{min}^{-1}$.

\subsection{Sample collection}

Tap water samples were collected from water tap in our laboratory, river water samples were collected from the Haihe River (Tianjin, China), and the wastewater samples were kindly supplied by a petrochemical plant and a printworks. These samples were all stored at the temperature of $4{ }^{\circ} \mathrm{C}$ after collection.

\section{Results and discussion}

In this study, parameters related to liquid-phase microextraction were optimized by utilizing the univariant method for simplifying the optimization procedure.

\subsection{Effect of salt addition}

The optimization of salt concentration was conducted by keep using $10 \mu \mathrm{l}$ of IL extractants for extraction $30 \mathrm{~min}$ at $60^{\circ} \mathrm{C}$, while adding varied amounts of sodium chloride $(\mathrm{NaCl})$ in $10 \mathrm{ml}$ of phosphate buffer solution $(\mathrm{pH} 12.0)$ spiked with $0.2 \mu \mathrm{g} \mathrm{ml}^{-1}$ of chlorinated anilines. Experiments demonstrated that for the four chlorinated anilines the extraction efficiency increased with the $\mathrm{NaCl}$ concentration up to $20 \%$ and followed by decreasing with further increasing of $\mathrm{NaCl}$ concentration. This result is in agreement with those reported in reference [8]. This phenomenon can be explained by the two simultaneously occurring processes: the salting out effect, and the electrostatic interactions between polar molecules and salt ions in sample solution. At the beginning, the former process plays the predominant role, but salt molecules begin to interact with analyte molecules when salt concentration increased further, which directly leads to the decrease of the respond. Therefore, $20 \%$ $\mathrm{NaCl}$ was adopted as the final addition in the following studies.

\subsection{Effect of temperature}

Usually, increasing temperature improves the evaporation of target compounds from the sample matrix to the headspace. In this experiment, we also investigated the effect of temperature (from 50 to $90^{\circ} \mathrm{C}$ ) on the extraction efficiency. Fig. 1 shows that temperature has significant effect on the extraction. With the increasing of the temperature, the extraction efficiency improved sharply as expected. Therefore, an extraction temperature of $90^{\circ} \mathrm{C}$ was considered as the optimum temperature in the following experiments.

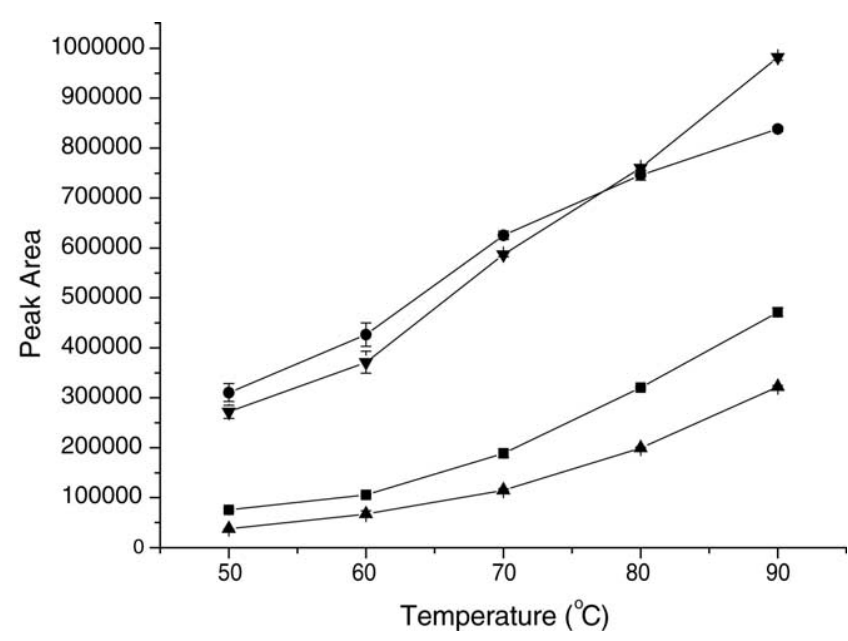

Fig. 1. Effect of temperature on the peak area of chlorinated anilines. Buffer solutions ( $\mathrm{pH} 12.0,10 \mathrm{ml})$ containing $20 \% \mathrm{NaCl}(\mathrm{w} / \mathrm{v})$ and spiked with $0.2 \mu \mathrm{g} \mathrm{ml}^{-1}$ of chlorinated anilines were extracted with $10 \mu 1\left[\mathrm{C}_{4} \mathrm{MIM}\right]\left[\mathrm{PF}_{6}\right]$

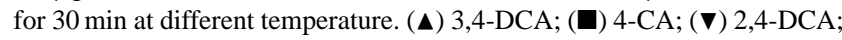
(๑) 2-CA. 


\subsection{Effect of sample $p H$}

For a weak organic base and acid, the extraction efficiency depends on the sample $\mathrm{pH}$. The sample solutions were often adjusted to appropriate alkalinity prior to extraction, so that the chlorinated anilines were de-ionized and their solubility in the sample solution reduced and extractability increased. Experiments demonstrated that the extraction efficiencies improved significantly with the increasing of $\mathrm{pH}$ up to 10 and then increased very slowly with further increasing of $\mathrm{pH}$. This is because the $\mathrm{p} K_{\mathrm{a}}$ values of 4-CA, 2-CA, 3,4-DCA and 2,4DCA were 4.15, 2.65, 2.00, 2.96, respectively [12,15], and the non-ionic chlorinated anilines predominate largely over the protonated ionic ones at $\mathrm{pH}>10$. Based on this investiga- tion, a samle $\mathrm{pH}$ value of over 10 is thus recommended and $\mathrm{pH} 12$ was adopted in the following studies.

\subsection{Effect of sample volume and extraction time}

During the headspace extraction process, sample volume can influence the magnitude of the headspace and thus might influence the extraction efficiency. For the optimization of sample volume, different volume of phosphate buffer solution (containing $20 \% \mathrm{NaCl}, \mathrm{w} / \mathrm{v} ; \mathrm{pH} 12.0$ ) spiked with $0.2 \mu \mathrm{g} \mathrm{ml}^{-1}$ of chlorinated anilines were extracted for $30 \mathrm{~min}$ at $90^{\circ} \mathrm{C}$. Experiments showed that the largest analytical response was obtained at $20 \mathrm{ml}$ of sample for all the studied chlorinated anilines. Further increasing of sample volume re-
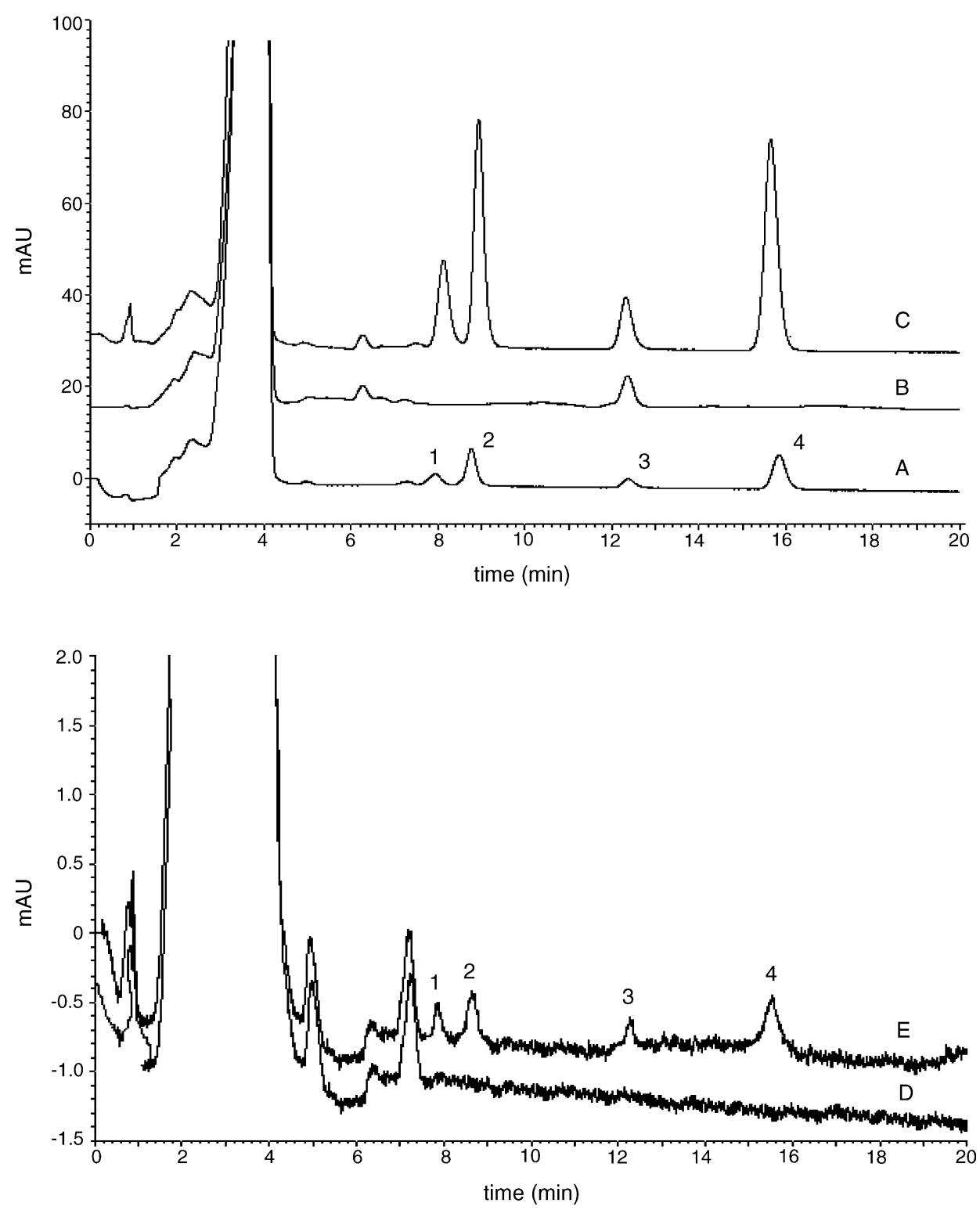

Fig. 2. Typical chromatograms of the four chlorinated anilines standard, wastewater sample and sample spiked with standard. (A) standard (25 $\left.\mu \mathrm{g} 1^{-1}\right)$; (B) wastewater sample from printworks; (C) wasterwater sample spiked with chlorinated anilines standard $\left(75.0 \mu \mathrm{g} 1^{-1}\right)$; (D) blank; (E) standard (1.0 $\left.\mu \mathrm{g} 1^{-1}\right)$. Peaks identified as: (1) 4-CA; (2) 2-CA; (3) 3,4-DCA; (4) 2,4-DCA. 
sulted in the decreasing of peak area, which can be explained by the two successive processes occurred in the extraction proceeding. At the beginning, the percentage headspace decreases with the increase of sample volume, which accelerates the diffusion of the analytes into the IL drop until saturation. If sample volume further increased, however, the analytes will take more time to transfer from the liquid to the headspace, thus the response begins to decrease. Therefore, $20 \mathrm{ml}$ was chosen as the optimal sample volume.

The optimization of extraction time was conducted at the above-optimized conditions. Experiments showed that the highest peak areas of the analytes were obtained at $30 \mathrm{~min}$ of extraction time, and further increasing of extraction time resulted in decreasing of peak areas. The probable reason is that, with the increasing of extraction time at the given high temperature, more water vapor will present in the headspace and the amount of analytes in IL drop decreased due to the distribution of anlytes between the IL and the water vapor phase. Another possibility is some chlorinated anilines might degraded at such a high extraction temperature $\left(90^{\circ} \mathrm{C}\right)$. According to this investigation, $30 \mathrm{~min}$ was chosen in the following study.

\subsection{Analytical performance and application}

Each analyte exhibited good linearity with correlation coefficient $r^{2}>0.999$ in the studied range $\left(5-100 \mu \mathrm{g} 1^{-1}\right.$ for 2-CA and 3,4-DCA, 1-150 $\mu \mathrm{gl}^{-1}$ for 4-CA, and $2.5-100 \mu \mathrm{g} 1^{-1}$ for 2,4-DCA). The repeatability was studied by five replicate experiments. This proposed procedure possessed good repeatability with relative standard deviations (R.S.D.s) in the range of 5-7\%. This is because IL is a very stable and non-volatile compound and there is no losing of extractant during headspace extraction. The limits of detection (LODs), estimated based on signal-to-noise ratio of 3 $(\mathrm{S} / \mathrm{N}=3)$, were in the range of $0.5-1.0 \mu \mathrm{gl}^{-1}$. The excellent characteristics of IL contributed a great to these very low LODs. At first, the involatile IL permits the headspace extraction at a high temperature of $90^{\circ} \mathrm{C}$ to make the four chlorinated anilines with high boiling point $\left(232^{\circ} \mathrm{C}\right.$ for 4 CA, $208.8^{\circ} \mathrm{C}$ for 2 -CA, $272^{\circ} \mathrm{C}$ for 3,4 -DCA and $245^{\circ} \mathrm{C}$ for 2,4-DCA [15]) diffuse into the headspace and thus be extracted more efficiently. In addition, the very high affinity between IL and chlorinated anilines [16] benefitted the trap of chlorinated anilines in IL.

The applicability of the proposed method was evaluated by analysis of real environmental samples including tap water, river water, and wastewater from a petrochemical plant and a printworks, respectively. The four chlorinated anilines were under their detection limits except that $88.2 \pm 5.8 \mu \mathrm{gl}^{-1}(n=3)$ of 3,4-DCA was detected in waste water from printworks. The spiking recoveries of standard at $25 \mu \mathrm{g} \mathrm{l}{ }^{-1}$ level $\left(75 \mu \mathrm{gl}^{-1}\right.$ for 3,4-DCA as it was detected at
$88.2 \pm 5.8 \mu \mathrm{g} \mathrm{l}^{-1}$ level in waste water from printworks) were in the range of $81.9-99.6 \%$. The typical chromatograms were shown in Fig. 2.

\section{Conclusions}

A novel procedure, high temperature headspace liquidphase microextraction based on ionic liquid, was proposed for the determination of chlorinated anilines in environmental water samples. The main advantages of the proposed procedure were the applicability of long-term headspace extraction at high temperature $\left(90^{\circ} \mathrm{C}\right)$ due to the non-volatility of $\mathrm{IL}$, and the high efficient trap of chlorinated anilines in IL due to the very high affinity between IL and chlorinated anilines. Therefore, the proposed method possessed high sensitivity (LODs $=0.5-1.0 \mu \mathrm{g} \mathrm{l}^{-1}$ ) and low influence of sample matrix (with recoveries of 81.9-99.6\%). On the other hand, the proposed method is rapid and easy to conduct as IL is compatible with HPLC column and thus IL with extracted analytes can be injected into the HPLC system for determination.

\section{Acknowledgements}

This work was jointly supported by the National Natural Science Foundation of China $(20377045,20477052)$ and the National Key Project for Basic Research (2002CB412308).

\section{References}

[1] L.M. Games, R.A. Hltes, Anal. Chem. 49 (1977) 1433.

[2] N. Boon, J. Goris, P. De Vos, W. Verstraete, E.M. Top, Appl. Environ. Microbiol. 67 (2001) 1107.

[3] M. Ucan, A. Gürten, A. Ayar, Colloids Surf. A: Physicochem. Eng. Aspects 219 (2003) 193.

[4] M.A. Valentovic, T. Yahia, J.G. Ball, S.K. Hong, P.I. Brown, G.O. Rankin, Toxicology 124 (1997) 125.

[5] Concise international chemical assessment document 48: Chloroanaline (4-), World Health Organization, Geneva, 2003.

[6] J. Jen, C. Chang, T.C. Yang, J. Chromatogr. A 930 (2001) 119.

[7] R.M. Riggin, T.F. Cole, S. Billets, Anal. Chem. 55 (1983) 1862.

[8] L. Zhao, L. Zhu, H.K. Lee, J. Chromatogr. A 963 (2002) 239.

[9] E. Papadopoulou-Mourkidou, J. Patsias, E. Papadakis, A. Koukourikou, Fresenius J. Anal. Chem. 371 (2001) 491.

[10] W. Chang, Y. Sung, S. Huang, Anal. Chim. Acta 495 (2003) 109.

[11] L. Zhu, C.B. Tay, H.K. Lee, J. Chromatogr. A 963 (2002) 231.

[12] J. Norberg, Å. Zander, J.Å. JÖnsson, Chromatographia 46 (1997) 483.

[13] J.-F. Liu, G.-B. Jiang, Y.-G. Chi, Y.-Q. Cai, Q.-X. Zhou, J.-T. Hu, Anal. Chem. 75 (2003) 5870.

[14] J.-F. Liu, Y.-G. Chi, G.-B. Jiang, C. Tai, J.-F. Peng, J.-T. Hu, J. Chromatogr. A 1026 (2004) 143.

[15] Dictionary of Organic Compounds, 6th ed., Chapman \& Hall Electronic Publishing Division, London, UK, 1996.

[16] D.W. Armstrong, L. He, Y.-S. Liu, Anal. Chem. 71 (1999) 3873. 